strongly to the Moon's never having been one part of the Earth: they are indicative, rather, of a Moon which originated from a nebular condensate under rather particular conditions in space. Studies of the ways in which plasmas and gases and particulate clouds behave under the action of an early solar wind are therefore of extreme importance if we are to learn more about the origin of planets-including the Earth itself.

How do atoms and molecules react in interstellar space and in the upper atmosphere of the Earth? What is the respective importance of electric phenomena and gas-dynamical forces in the early solar system? What is the accretion mechanism and the irradiation history of meteoroids? How were asteroids and comets formed? These are some of the fundamental questions raised by the experts who contributed to this volume.

Much may be learned-and cheaply in comparison with the cost of the manned spaceflight programme-by careful, protracted analyses of the smaller objects in the solar system: the dust in the upper atmosphere and in space, the asteroids, and the satellites of other planets. This may be regarded as a realistic view of one of the next steps that scientists may take in their continuing attempts to discover the origin of the planets.

This excellent book, for solar system specialists, physicists, chemists and astronomers, details how these problems are being tackled. At the end of each technical paper, it records valuable discussions between participants at the Nobel Symposium 21. Names such as Alfvén, Anders, Arrhenius, Massey, Millman, Petrov and Runcorn feature in the main text and in the discussions; and the book is undoubtedly well worth the price.

G. FIELder

\section{Homage to Meyerhof}

Molecular Bioenergetics and Macromolecular Biochemistry. Edited by H. H. Weber. Pp. viii +197 . (Meyerhof Symposium, Heidelberg, July 1970.) (Springer: Berlin and New York, 1972.) 79 DM; \$25.10.

"DisTinction develops if nurtured by distinction," wrote Sir Hans Krebs (Nature, 215, 1441; 1967) in tracing the factors that contribute to the making of successful scientists. It is thus perhaps not surprising that, among those who were Otto Meyerhof's former pupils and associates, or whose work was in some way profoundly influenced by him, and who gathered in Heidelberg in July 1970 to commemorate the life and work of that great biochemist, were seven Nobel Laureates as well as many others who have made major contributions to biochemical knowledge. And it is, perhaps, also not surprising that the lectures given in this symposium are uniformly good: after all, here are the masters, talking about their own achievements. Thus, after a biographical sketch of Meyerhof (by his first pupil, H. H. Weber) and of his ancestry (by H. A. Krebs), there are lucid surveys of the structure and mechanism of action of aldolase (by B. L. Horecker), of the multi-enzyme complexes involved in fatty acid synthesis (by F. Lynen), of chain initiation factors in protein synthesis (by $\mathrm{S}$. Ochoa), and of the amino-acid polymerizations involved in the formation of gramicidin and tyrocidin (by F. Lipmann). There are two fine papers on the structure (by K. C. Holmes) and the activity (by Annemarie Weber) of the actomyosin system of muscle. A fascinating discussion of the genetic basis of carcinogenesis (by L. Sachs) is followed by three equally fine papers on chemical (by M. Eigen) and physiological (by W. Hasselbach and, in absentia, by D. Nachmansohn) aspects of membrane processes. As an act of scientific homage to, and of pious remembrance of, a great biochemist and an obviously much-loved person, this symposium cannot be faulted.

One also cannot but applaud the peculiar appropriateness of the occasion. In 1968, the Volkswagen Foundation endowed an Otto Meyerhof Chair at the Weizmann Institute of Science, in Rehovot (Israel), to honour the memory of Meyerhof and to strengthen the relations between Israeli and German scientists. The symposium was planned, at the suggestion of Professor D. Nachmansohn, to commemorate that event, with the participation of German and Israeli scientists: indeed, one of the lecturers, Professor Sachs, is the first holder of the Meyerhof Chair. The symposium was accordingly arranged by a group of the Weizmann Institute, in consultation with $\mathrm{Nach}$ mansohn, Ochoa and the Organizing Chairman; it was sponsored by the Institute and the German Gesellschaft für Biologische Chemie. Nothing, surely, could have been more fitting to the occasion and more appropriate to the intention.

But do the proceedings of this symposium make a satisfactory book? With genuine regret, I must conclude that they do not. Such coherence as there is is provided solely by the sentiments of the occasion: as apparent from the contents listed above, there is no cohesive scientific theme. And, alas, there is also little novelty. The substance of much of the material has appeared in print on previous occasions and is now re-reproduced. Indeed, the German text of one excellent lecture is illus- trated by diagrams, captioned in English, that must surely be familiar to most likely readers of this book and that have obviously been taken directly from another and widely-read publication.

Although this volume will be rightly treasured by those who attended the symposium, as a record of a unique occasion, I cannot imagine that there will be many private purchasers of this very expensive little book.

H. L. KornberG

\section{Distribution Theory}

Multivariate Analysis. By Anant M. Kshirsagar. Pp. xiv +534 (Marcel Dekker: New York, July 1972.) $\$ 19.50$.

This book covers the advanced theory of multivariate analysis, concentrating to a large extent on distributional problems. It is a somewhat frightening volume to glance through, as inevitably it has many pages of complicated algebraic expressions; I approached it with some trepidation. It must be confessed, however, that Professor Kshirsagar handles his material so clearly and logically that difficulties are eased. It would be misleading to suggest that they vanish; this is a hard book to read. It is aimed largely at the postgraduate student of mathematical statistics.

It is also misleading to suggest that practical workers seeking guidance in the use of multivariate analysis would find the book helpful. Although the author occasionally presents a brief (and sometimes illuminating) paragraph on practical implications, the text is almost entirely theoretical.

In his presentation, the author makes great use of elegant matrix transformations and random orthogonal transformations, and many of his derivations are relatively neat and concise. Regression analysis plays a key role in the development, and Professor Kshirsagar emphasizes the central part canonical variables and correlations have in multivariate analysis.

Although practical illustrations are not given, there are plenty of references to papers where multivariate analysis has been used. Another feature is a large collection of theoretical exercises which will be valuable to the teacher and student. The appearance of the book is a little off-putting, it apparently having been reproduced directly from a typescript. In view of this, the price seems rather high. There are a number of misprints, and at times the author's style is a little garbled.

To sum up, this is a useful compilation of theoretical results on distribution theory and significance testing in multivariate analysis. It is quite comprehensive, but does not cover factor analysis.

J. F. ScoTt 